\title{
Study on Hot Diaphragm Forming Process of CCF300/5228A Composites
}

\author{
Li Yana, Xuefeng An \\ National Key Laboratory of Advanced Composites, AVIC Composites Technology Center, Composites Company LTD of AVIC, Beijing \\ 100095, China
}

\begin{abstract}
In this paper, the hot diaphragm forming process of CCF300/5228A composite was studied through selfdeveloped hot diaphragm forming equipment. CCF300/5228A prepreg for the hot diaphragm forming process was modified. Combined the physical and chemical experiment of CCF300/5228A prepreg with modeling analysis of deformation behavior, the processing parameters of CCF300/5228A composites for hot diaphragm forming process were selected and optimized. Composites with $\mathrm{C}$-shaped structure were fabricated according to the optimum parameters of hot diaphragm forming process, and final C-shaped composites could satify the requirments of design.
\end{abstract}

\section{Introduction}

Composites offer an attractive potential for reducing the weight of high-performance structures as consequences of their high specific strength and stiffness. At present, for the large thickness composite wing spar of aircraft and composite hat-shaped stringers, the traditional manual laying method has low efficiency and low stability. Automatic technology has been adopted in the preparation of the wing spar and composite hat-shaped stringers in foreign countries, which can improve the manufacturing efficiency and product quality by reducing the influence of human factors. In the automated manufacturing process, it is included that first composite flat pre-form is prepared by Automated Tape Laying, and then the pre-form close to the final shape is obtained by hot diaphragm forming process, last the composite preform is solidified by autoclave forming process.

The hot diaphragm forming process is completed at a certain temperature, and the composite flat pre-form changed with the change of curvature, and the slipping deformation of the pre-form layer occured. In order to avoid the crease and fracture of the fiber during the slipping of the layers, the deformation of the flat pre-form and the interlayer slip must be matched. Over last few years, many researchers has carried out extensive investigations on the hot diaphragm-forming process[1-8]. The hot diaphragm forming process has been successfully applied to large components such as the Boeing 777, the V22 composite stringers and the A400M wings, and it has developed into an important low-cost manufacturing technology[9-13]. However, there are few studies on the hot diaphragm forming process of thermosetting composite materials in China[14-18]. Moreover, the domestic hot diaphragm forming technology is still in the experimental stage, lacking relevant theoretical and technical basic research, and lacks the domestic prepreg system suitable for hot diaphragm forming process.

In this paper, the research on the hot diaphragm forming process of CCF300/5228A composites was carried out through self-developed hot diaphragm forming equipment. CCF300/5228A prepreg for the hot diaphragm forming process was modified. Combined the physical and chemical experiment of CCF300/5228A prepreg with modeling analysis of deformation behavior, the processing parameters of CCF300/5228A composites for hot diaphragm forming process were selected and optimized. Composites with $\mathrm{C}$-shaped structure were fabricated according to the optimum parameters of hot diaphragm forming process, and final C-shaped composites could satify the requirments of design.

\section{Experimental details}

\subsection{Materials}

A high temperature carbon fiber/epoxy resin undirectional prepreg CCF300/5228A was a product of Composites Company LTD of AVIC. The diaphragms of SL700 and SL800 and other auxiliary materials were purchased from American Airtech company.

\subsection{The hot diaphragm forming process}

In this paper, the hot diaphragm forming process of CCF300/5228A composites was studied through the selfdeveloped hot diaphragm forming equipment, and the hot diaphragm forming equipment and principle diagram were shown in Figure 1.

The flat pre-form was held in the hot diaphragms, which was raised or lowered with the press frame to close or leave the mold. The vacuum degree between the

a Corresponding author: yanli0827@163.com 
double hot diaphragms was adjusted to control the degree of clamping of the diaphragm for prepreg. The hot diaphragm frame and the molding table were sealed with a sealing ring and the molding table was covered with vacuum holes. Through vacuumizing between the diaphragm and molding table, the prepreg was finally fitted with the mold. The infrared heater was controlled by the partition. At the initial stage of the process, the resin matrix was heated and softened in order to make the prereg fitted the mold. And then rmatained the temperature further and the preforming of the pre-form was completed.
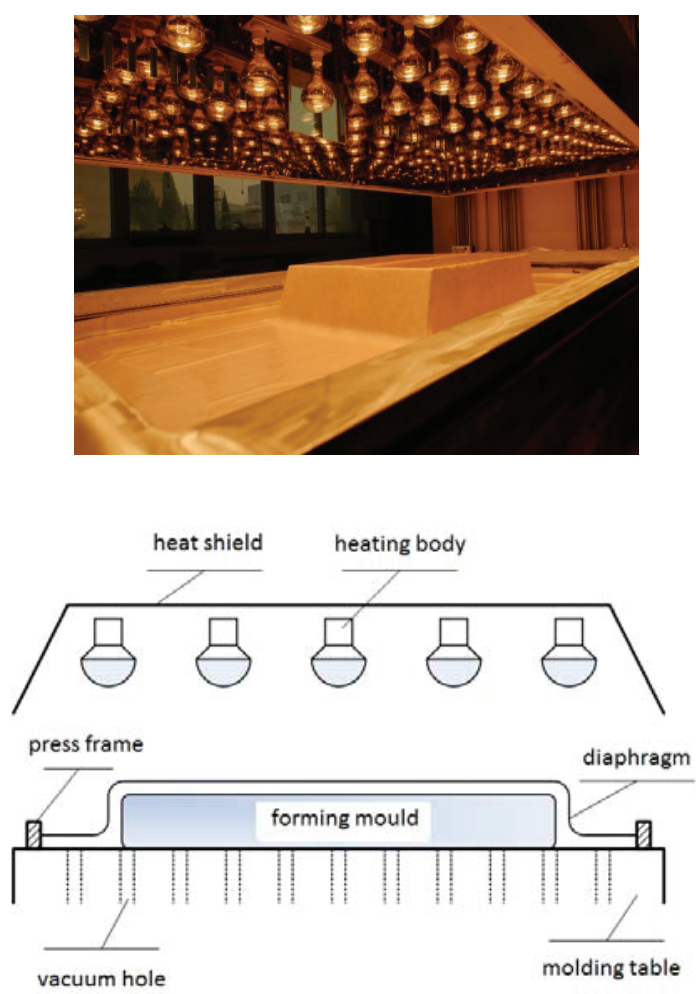

Figure 1. The hot diaphragm forming equipment and principle diagram

\section{Results and discussion}

\subsection{CCF300/5228A prepreg for hot diaphragm forming}

CCF300/5228A prereg was a high temperature curing carbon fiber/epoxy resin undirectional prepreg. Its mechanical properties, physical and chemical properties and process properties had been relatively mature. But there were certain problems to apply it to hot diaphragm forming process. It was necessary to modify the resin to meet the requirements of the hot diaphragm forming process. The DSC diagram of the 5228A resin was shown in Figure 2 and the viscosity - temperature curve of the 5228A resin was shown in Figure 3. As seen from Figure 2 and Figure 3, the initial reaction temperature of 5228A resin was $116{ }^{\circ} \mathrm{C}$, and solidified reaction enthalpy was $436 \mathrm{~J} / \mathrm{g}$. When the lowest viscosity of the resin appeared, the temperature was around $120^{\circ} \mathrm{C}$.

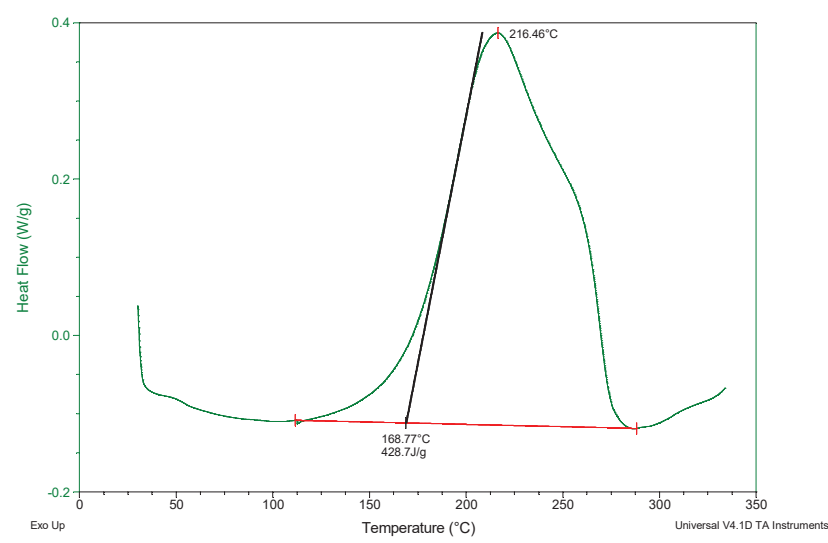

Figure 2. The DSC diagram of the 5228A resin

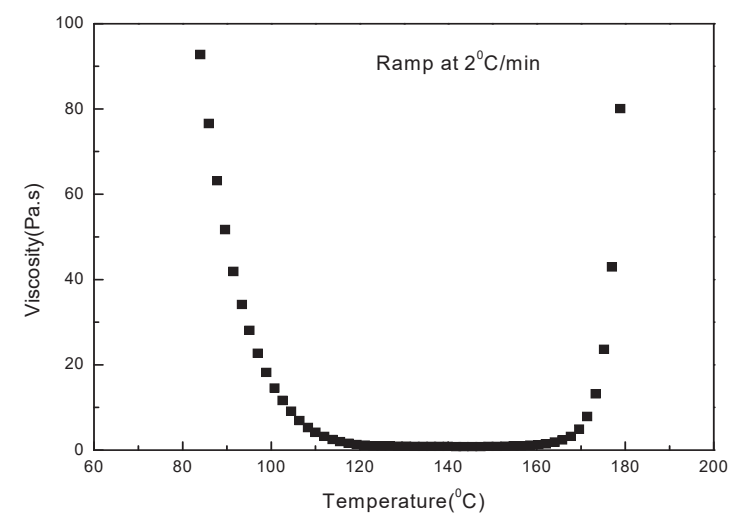

Figure 3. The viscosity - temperature curve of the 5228A resin

In order to improve the deformation and slipping ability driven by external forces, the special prereg for hot diaphragm forming process was modified on the basis of CCF300/5228A prereg. The method to modify the prereg was improving the resin content of standard CCF300/5228A prereg appropriately. There were more resin between layers, which was beneficial to the deformation of the inerlayers and the slipping between layersr, thus improving the overall deformation performance of the pre-form. Through the experiment, the processing parameters of CCF300/5228A for hot diaphragm forming process were determined as follows: the fiber volume fraction was $55 \%$, the fiber surface density was $145 \mathrm{~g} / \mathrm{m}^{2}$, the resin surface density of prepreg was $83 \mathrm{~g} / \mathrm{m}^{2}$, and the weight fraction of resin was $35 \%$.

\subsection{The diaphragm for hot diaphragm forming process}

The diaphragm required good ductility and high temperature resistance. The mechanical properties of the two diaphragms SL700 and SL800 were tested, and the test results were shown in Table 1.

As shown in Table 1, the elongation rate of the diaphragm SL700 was much higher than that of SL800, but SL800 had more tensile strength than SL700, according to the theory and actual test results, both SL700 and SL800 diaphragms could satisfy the requirement of hot diaphragm forming process. 
Table 1. Mechanical propertites test results of diaphragms

\begin{tabular}{|c|c|c|c|c|}
\hline \multirow{2}{*}{ Project } & \multicolumn{2}{|c|}{ SL700 } & \multicolumn{2}{c|}{ SL800 } \\
\cline { 2 - 5 } & $\begin{array}{c}\text { Tensile } \\
\text { strength } \\
\text { (Mpa) }\end{array}$ & $\begin{array}{c}\text { Elongation } \\
(\%)\end{array}$ & $\begin{array}{c}\text { Tensile } \\
\text { strength } \\
(\mathrm{MPa})\end{array}$ & $\begin{array}{c}\text { Tensile } \\
\text { strength } \\
(\%)\end{array}$ \\
\hline 1 & 35.71 & 819.96 & 44.07 & 502.32 \\
\hline 2 & 37.83 & 965.13 & 47.40 & 515.57 \\
\hline 3 & 36.90 & 1043.95 & 35.80 & 423.62 \\
\hline 4 & 36.99 & 681.20 & 46.65 & 573.75 \\
\hline 5 & 32.36 & 700.68 & 45.95 & 484.41 \\
\hline Average & 35.96 & 842.18 & 43.98 & 499.94 \\
\hline
\end{tabular}

\subsection{Modeling analysis of deformation behavior of CCF300/5228A prereg}

The research on deformation behavior of CCF300/5228A prereg for hot diaphragm forming had been done through physical and chemical tests and computational simulation. Physical and chemical experiments included DSC, DMA and rheology, and the simulation software was from the PAM-FORM of ESI company. The test results of DSC, DMA and rheology were used as simulated input of PAM-FORM. The results of simulation were shown in Figure 4.

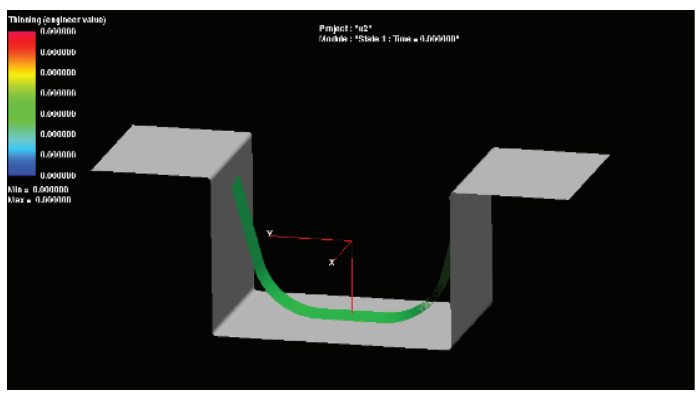

(a) $\mathrm{t}=0$

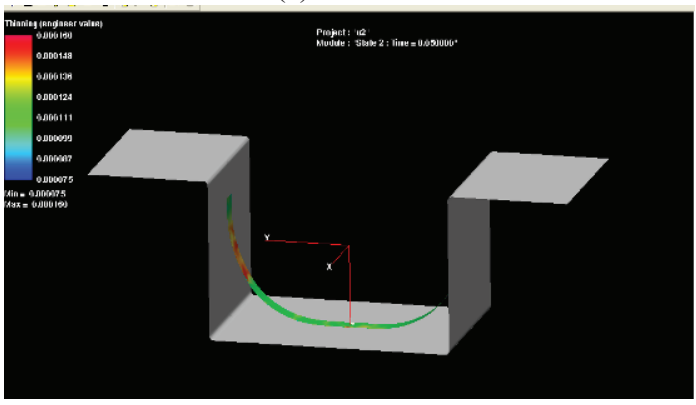

(b) $\mathrm{t}=0.5 \mathrm{~s}$

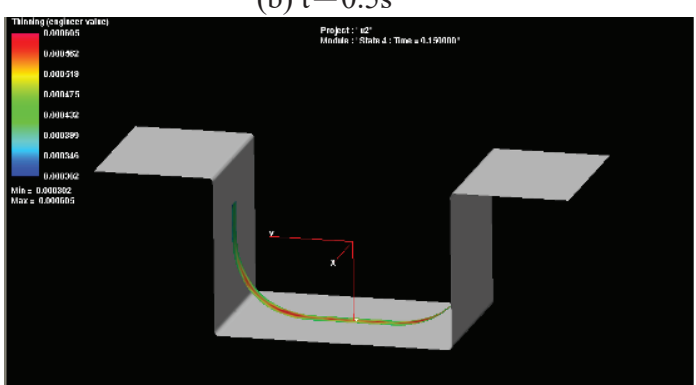

(c) $\mathrm{t}=0.15 \mathrm{~s}$

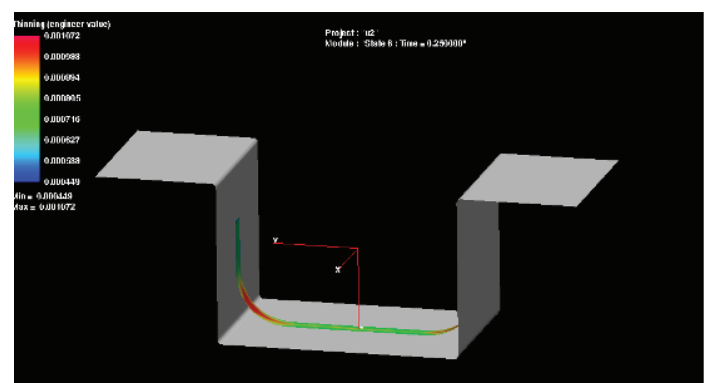

(d) $\mathrm{t}=0.25 \mathrm{~s}$

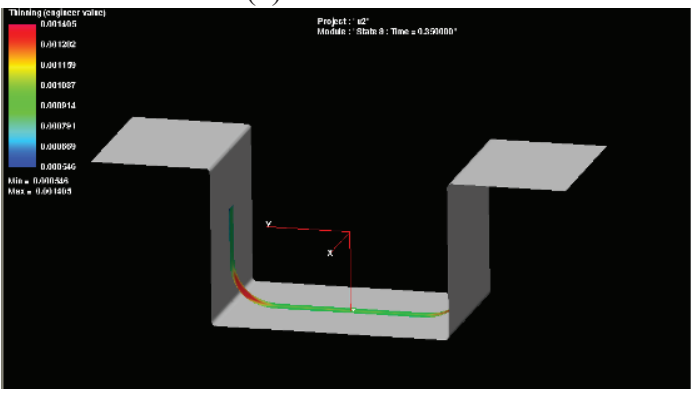

(e) $\mathrm{t}=0.35 \mathrm{~s}$

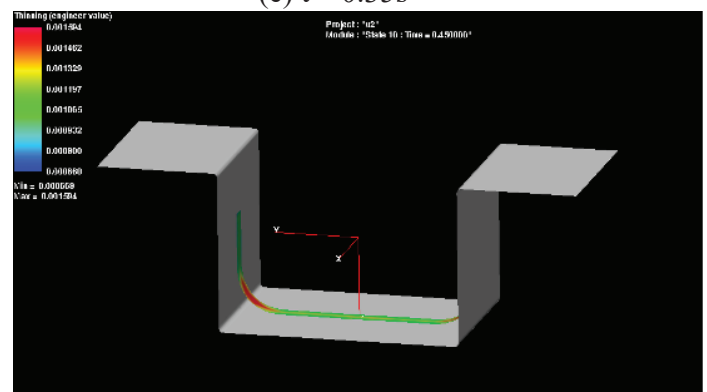

(f) $\mathrm{t}=0.45 \mathrm{~s}$

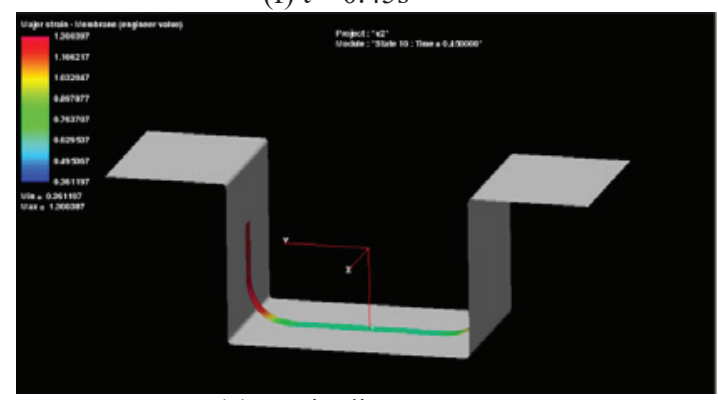

(g) Strain diagrams

Figure 4. Deformation process and strain distribution of layer with $[45 / 90 /-45 / 0]$

$(a \sim f$ : Deformation diagrams at different times, g: Strain diagrams of deformation process)

As indicated in Figure 4, in the process of hot diaphragm forming, first the bottom surface of typical specimen was fitting, and then the pre-form and the mould were gradually fitted and typed by slipping between layers to ensure that the bending angle was formed. Therefore, in the whole process of hot diaphragm forming, the bottom had a small strain, and the strain on both sides was large, which resulted in slipping between layers on the side.

\subsection{Selection and preliminary optimization of parameters of hot diaphragm forming process}




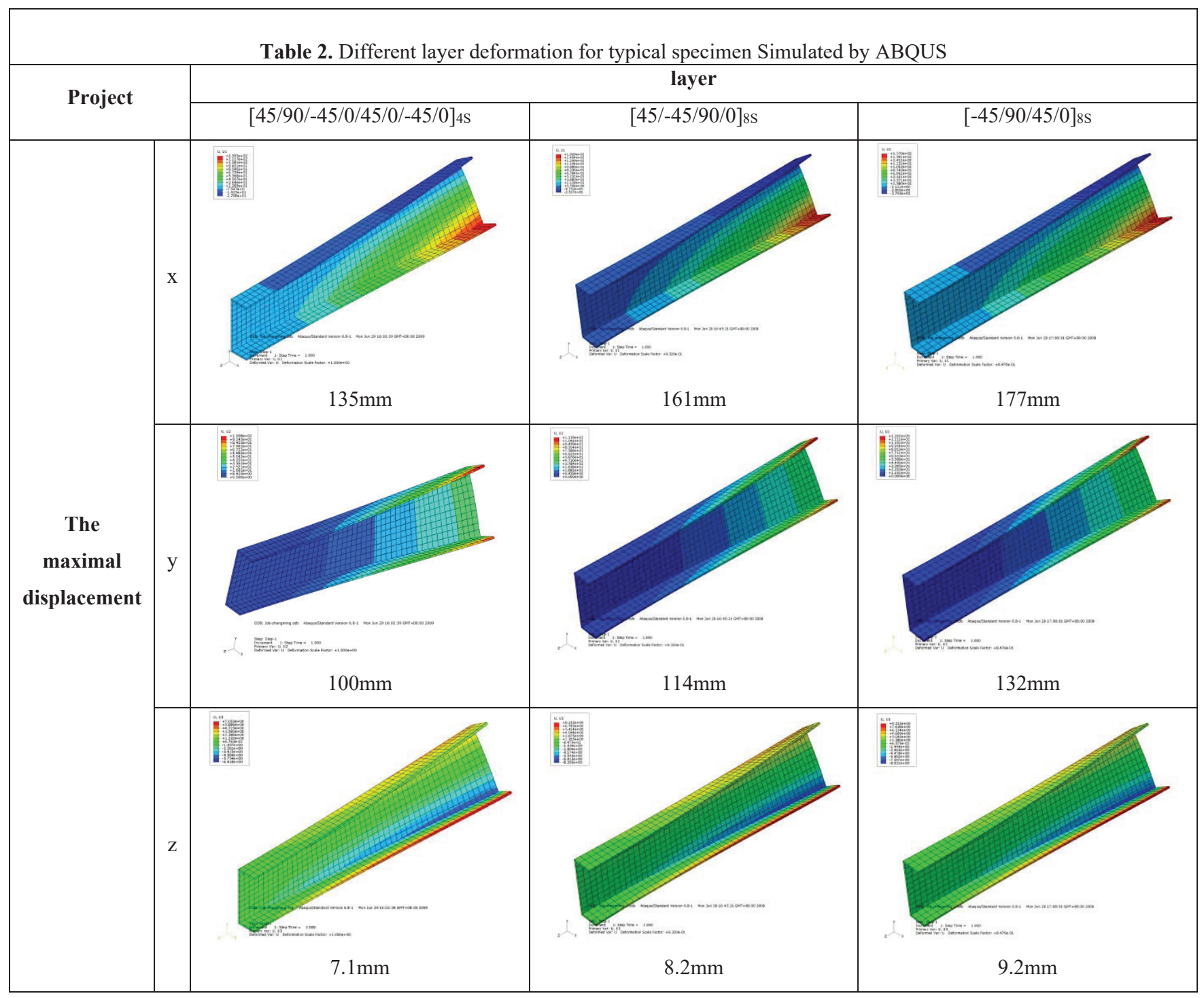

Table 2 showed the deformation graphs of $\mathrm{x}, \mathrm{y}$ and $\mathrm{z}$ directions under specific loads of the typical specimen with different layers were calculated by ABUQS software. As shown in Table 2, the deformation of layer with $[45 / 90 /-45 / 0 / 45 / 0 /-45 / 0]_{4 S}$ in three directions was less than layers with $[45 /-45 / 90 / 0]_{8 \mathrm{~s}}$ and $[-45 / 90 / 45 / 0]_{8 \mathrm{~s}}$. The minimum deformation and stress were obtained from layer with $[45 / 90 /-45 / 0 / 45 / 0 /-45 / 0]_{4 \mathrm{~S}}$. The composites with $\mathrm{C}$-shaped structure prepared by this layer had larger axial stress, which could undertake the main load. Through the above analysis, it was determined that the optimal layer of typical specimen was [45/90/-45/0/45/0/$45 / 0]_{4 S}$.

In hot diaphragm forming process, processing temperature determined resin flowability as well as the deformability of prepreg, thus influenced the forming quality of pre-form. The best deformation temperature for CCF300/5228A prereg was $120{ }^{\circ} \mathrm{C}$ by analyzing the results of DSC and DMA. C-shaped composite spar of CCF300/5228A was fabricated at $120{ }^{\circ} \mathrm{C}$ as hot diaphragm preforming temperature and then was cured by autoclave process, and finally the spar quality could satisfy the requriment of design, as shown in Figure 5(a). In Figure 5(b), on the side of C-shaped composite spar, it appeared roughly equispaced interlayer stagger due to the smooth slipping between the fiber layers. In Figure 5(c), the fiber at the corner of composite spar had smooth transition, and there were no wrinkless on the inside of the corner and no rich resin area on the outside. That also validated the calculation results of the PAM-Form.

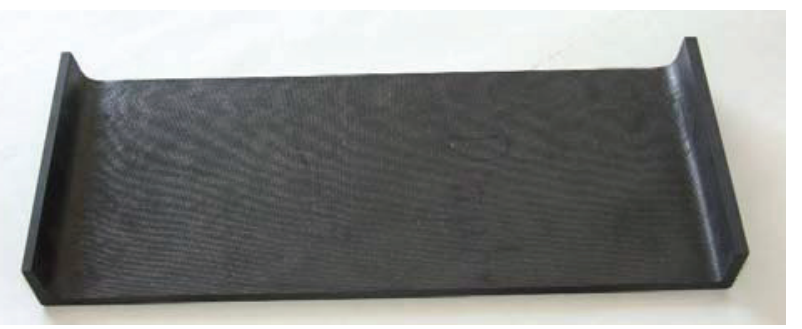

(a) spar 


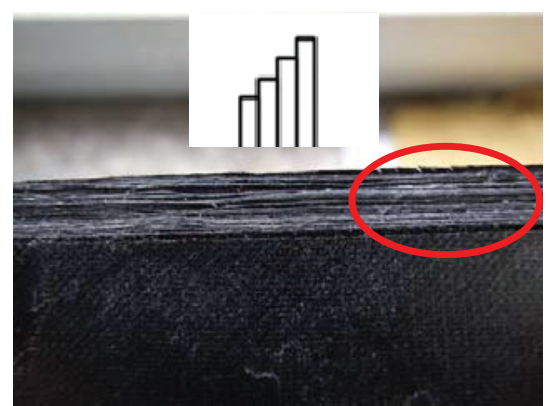

(b) interlayer slipping

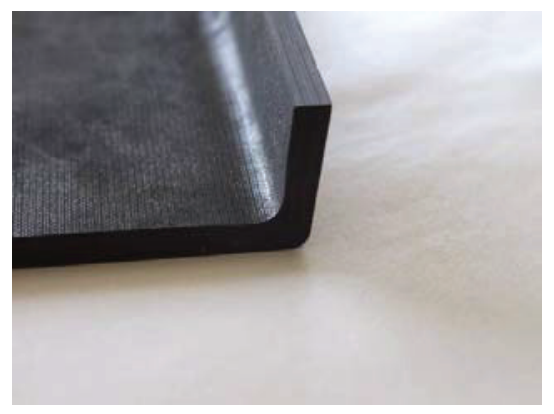

(c) typical corner

Figure 5. Composites C-shaped spar of CCF300/5228A by hot diaphragm forming process

\section{Conclusions}

Following conclusions were drawn from this work:

(1) The processing parameters of CCF300/5228A were determined for hot diaphragm forming process as follows: the fiber volume fraction was $55 \%$, the fiber surface density was $145 \mathrm{~g} / \mathrm{m}^{2}$, the resin surface density of prepreg was $83 \mathrm{~g} / \mathrm{m}^{2}$, and the weight fraction of resin was $35 \%$.

(2) The test results of DSC, DMA and rheology were used as simulated input of PAM-FORM. The results of simulation was as follows: in the process of hot diaphragm forming, first the bottom surface of typical specimen was fitting, and then the pre-form and the mould were gradually fitted and typed by slipping between layers to ensure that the bending angle was formed. Therefore, in the whole process of hot diaphragm forming, the bottom had a small strain, and the strain on both sides was large, which resulted in slipping between layers on the side.

(3) The hot diaphragm forming temperature had been identified as $120{ }^{\circ} \mathrm{C}$. On the side of C-shaped composite spar, it appeared roughly equispaced interlayer stagger due to the smooth slipping between the fiber layers. The fiber at the corner of composites spar had smooth transition, and there were no wrinkles on the inside of the corner and no rich resin area on the outside. The spar quality could satisfy the requriment of design. That also validated the calculation results of the PAM-Form.
1. P J Mallon, C M O’Bradaigh, R B Pipes. Compos 20(1): 48-56 (1989).

2. A J Smiley and R B Pipes. J Thermoplast Compos Mater, 1: 298-321 (1988).

3. C M O’Bradaigh, P J.Mallon. Compos Sci Technol 35: 235-255 (1989).

4. G N Labeas, V B Watiti and C V Katsiropoulos. J Thermoplast Compos Mater, 21: 353-370 (2008).

5. H Bersee, A Beukers. Compos Pt A, 33(7): 949-958 (2002).

6. S G Pantelakis, E A Baxevani. Compos Pt A, 33: 459-470 (2002).

7. J Krebs, K Friedrich, D Bhattacharyya. Compos Pt A, 29(A): 183-188 (1998).

8. K J Channer, W Cosgriff, G F Smith, et al. Plast Compos, 21: 1629-1635 (2002).

9. S Delaloye, M Niedermeir. Compos Manuf, 6(3): 135-144 (1995).

10. S G Pantelakis, E A Baxevani. Compos Part A, , 33(4): 459-470 (2002).

11. J Shen, $\mathrm{H}$ G Xie. Fiber Reinforced Plastics/Composites, 5: 48-54 (2006).

12. D H Liu. Fiber Composites, 2: 41-44 (2012).

13. Y L Chen. Aeronautical Manufacturing Technology, 10: 32-35 (2008).

14. Z P Kuang, L Dai, X M Wang. Beijing: china science \& technology press, 613-615 (2010).

15. Z E Wu. Aeronautical Manufacturing Technology, 25: 113-116 (2009).

16. N H Yang, Y Yang, Y B Yu. Beijing: The 1st China International Congress on Composite Materials, 908912 (2014).

17. X X Bian, Y Z Gu, J Sun, et al. Fiber Reinforced Plastics/Composites, 5: 45-50 (2013).

18. S Yao, M Li, Y Z Gu. Journal of Beijing University of Aeronautics and Astronautics, 39: 95-99 (2013).

\section{References}

